\title{
THE SYNTHETIC DESCRIPTION OF THE RESULTS, SCIENTIFIC ACHIEVEMENTS AND PRACTICAL APPLICATIONS OF THE EUREKA - IMPERJA PROJECT, E3496! - "IMPROVING THE FATIGUE PERFORMANCE OF RIVETED JOINTS IN AIRFRAMES"
}

\author{
Jerzy Kaniowski \\ Institute of Aviation, Warsaw, Poland
}

Consortium Members:

IoA Institute Of Aviation, Poland, Coordinator

Polish Aviation Factory - PZL Mielec, Poland

AGH - University of Science and Technology, Faculty of Mechanical Engineering \& Robotics, Poland

UTP - University of Technology and Sciences in Bydgoszcz, Faculty of Mechanical Eng., Dept. of Machine Design, Poland

WAT - Military University of Technology, Inst. of Materials Science and Applied Mechanics, Dept. of General Mechanics, Poland

Stresstech Oy., Finland

Evektor Spol. S.R.O., Czech Republic

\section{INTRODUCTION}

The goal of the project was to increase the fatigue life of the riveted joints in order to achieve an increase in the aircraft service life, a smaller number of inspections and, consequently, lower aircraft operating costs. This goal was achieved by the analysis and optimization of the riveting process as well as by improving the fatigue life prediction methods (crack initiation and propagation).

The project outcomes enable a more precise fatigue life estimation and an increase in Time Before Overhaul (TBO) for currently used aircraft, as well as optimize the design of new aircraft from the fatigue point of view.

All activities in the aerospace area are subjected to regulations. Significant formal changes have taken place in the aircraft design regulations in recent years. The European Aviation Safety Agency, established in the EU in 2002, introduced the Certification Specification (CS), which contains the airworthiness code and acceptable means of compliance for particular types of an aircraft. In 1997, in the US, the Code of Federal Regulations (CFR) was introduced relating to all areas of life including politics, law and economy. The Title 14 CFR contains aircraft design regulations. Other changes included the introduction of the damage tolerance as a basic methodology for commuter aircraft. The standards recommended by the Certification Specification and the Title 14 CFR are the American Society for Testing and Materials (ASTM) Standards for Material Tests and the NASM1312 Standard Practice Fastener Test Method Standards for Riveted Joint Tests.

The strong correlation between the service life and Direct Operating Costs (DOC) of the aircraft was proved by the calculations carried out according to the methodology described in the book Airplane Design by Jan Roskam, part 1, 8. For example, extending the service life of the 19-seats commuter category turboprop-powered airplane from 8000 to 32000 hours could decrease its DOC to $47 \%$, Fig. 1. 


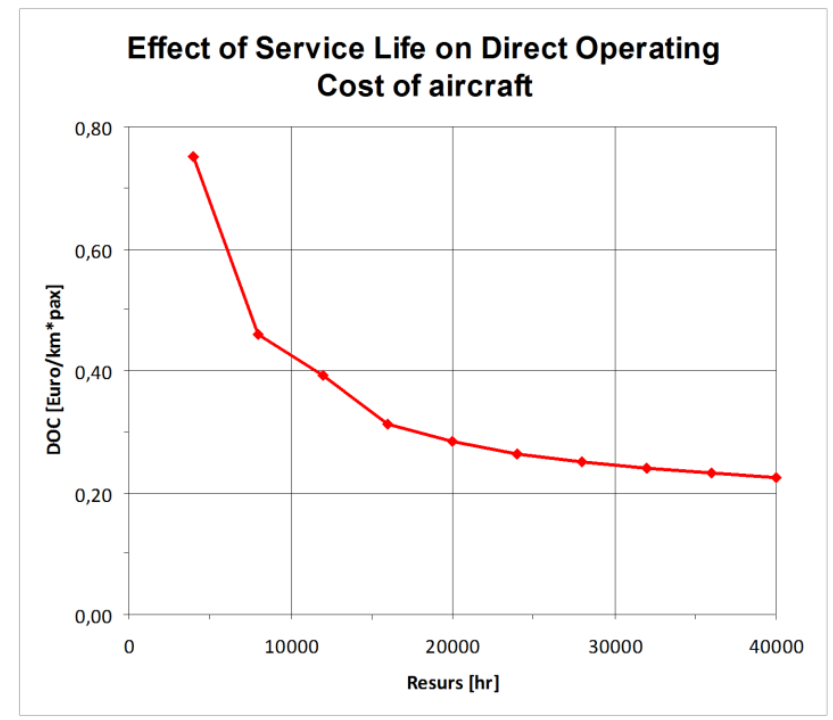

Fig. 1. Effect of Service Life on Direct Operating Cost of aircraft [4].

The IMPERIA project consists of two parts: basic and applied research.

\section{BASIC RESEARCH}

The program of basic research was developed based on the wide literature available $[2,3,4]$. The authors assumed that experimental and theoretical results should be valuable for the aircraft life estimation and manufacturing. Some research topics known from the literature were repeated for sheets and rivets materials used in the aerospace industries in Central Europe.

\subsection{Experimental determination of mechanical properties of airframe skin sheet and rivets material}

A wide range of tests of the materials used in the riveted joints were conducted. They covered monotonic and fatigue tests (high- and low-cylce) as well as fatigue crack growth tests. Two sheet materials (D16AT [and its variation D16CzATW] and 2024-T3), two types of anti-corrosion layer (alclad and anodised) and three rivet materials (PA24, PA25 and 2117) were compared. The tests performed enabled the comparative analysis of the above mentioned alluminium alloys used in the Polish aerospace industry (D16, PA24 and PA25) as well as two types of alloys used in the West (2024 and 2117).

The chemical composition of D16ATW and D16CzATW sheets alloys (according to their standards and our own chemical composition tests) corresponds to the appropriate chemical composition alloys 2024-T3 Alclad and 2124-T3 Alclad. These alloys exhibit slightly higher monotonic strength properties $\left(\mathrm{Re}_{0.2} \%, \mathrm{R}_{\mathrm{m}}, \mathrm{E}\right)$ on the direction parallel in the rolling direction than in the transverse direction. The 2024-T3 and D16CzATW alloys showed a distinct yield strength in this direction. The study of fatigue crack growth for CA loads, and programmable test sequences loads according to miniFALSTAFF revealed that the D16CzATW and 2024-T3 alloys behaved similarly.

The chemical composition of PA24 alloy corresponds to the chemical composition of 2117 alloy (AD material class), from which universal rivets MS 20470-AD are made. The monotonic properties of these alloys are similar. PA25 alloy has higher mechanical properties compared to PA24 and 2117 alloys.

During the tests, the passive IR-thermography and the acoustic emission were used as complementary methods. This allowed for widening the knowledge about the investigated materials. The Portevin-Le Chatelier effect was observed in the monotonic tests, especially for the 
specimens cut lengthwise in the rolling direction (Fig. 2). This phenomenon was also visible in the the elevated temperature tests (for the range of $25^{\circ} \mathrm{C}$ to $200^{\circ} \mathrm{C}$ ). 2024-T3 and D16UTW alloys have a distinct thermoelastic-plastic boundary (Fig. 3) and it is higher than the yield strength by $4.1 \%$ and $9.9 \%$ respectively.
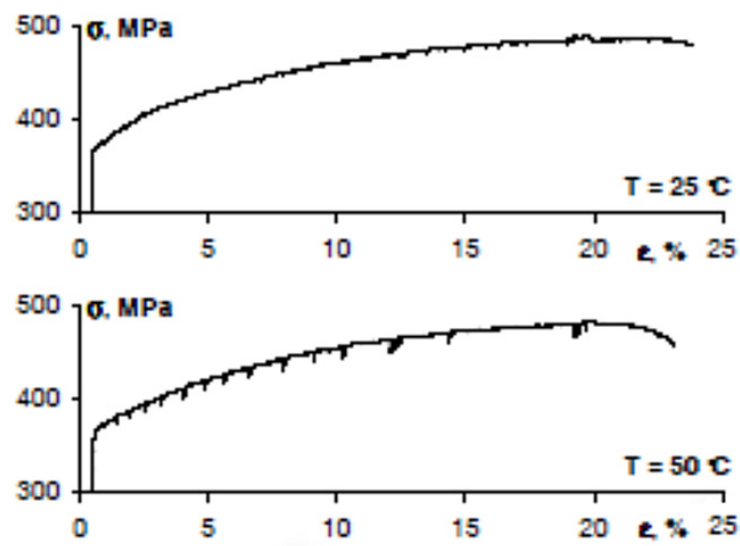

Fig. 2. Graphs recorded during the tensile test of the specimens from the 2024-T3 aluminum sheet cut along the rolling direction [16].

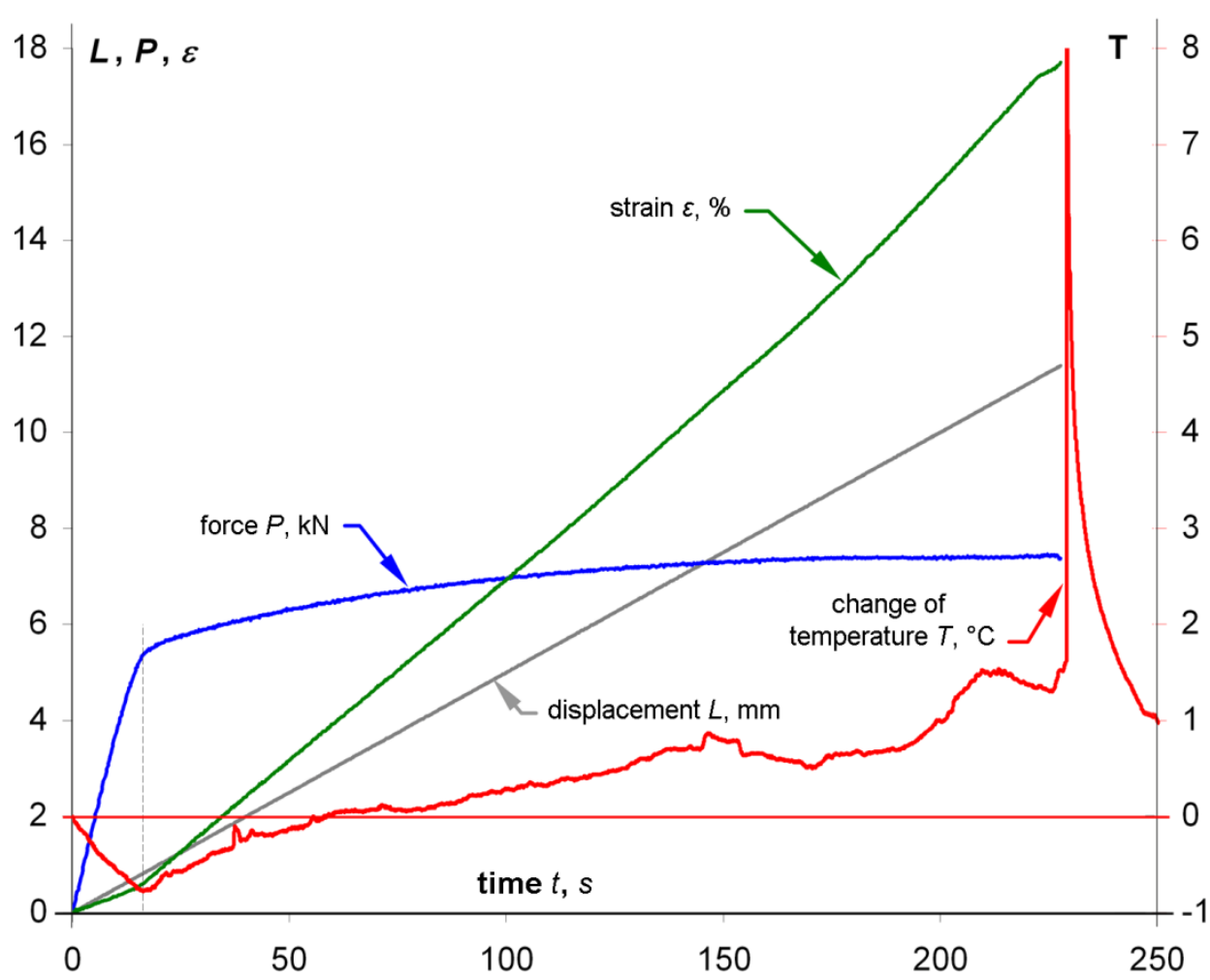

Fig. 3. An example of the time course of the quantities recorded during the monotonic tensile test of a specimen made of 2024-T3 aluminum alloy sheet with a thickness of 0.05" (1.27 mm) cut along the rolling direction as well as the temperature-tension dependence [16].

Moreover, the tear and shear tests for various squeezing forces were carried out. 


\subsection{Experimental investigation into the effect of various aspects of the riveting technique on the residual stress/strain field around the rivet hole}

The methodology of the residual stress measurements for the riveted joints with use of the XSTRESS3000 X-ray difractometer (XRD) was developed, Fig. 4 [5]. This methodology allows elliminating the effect of the driven/manufactured head shadow on the measurements. An extensive programme of residual stress measurements near the rivets was carried out. The measurements concerned specimens with various types of rivets used in the PZL Mielec (countersunk and brazier, standard and with a compensator) and various riveting technologies (normal and NACA), Fig. 5. The specimens were riveted with the force control. It has been demonstrated that rivets with compensators and the NACA technology cause higher compressive tangential stress on the manufactured head side. This significantly improves the fatigue life.

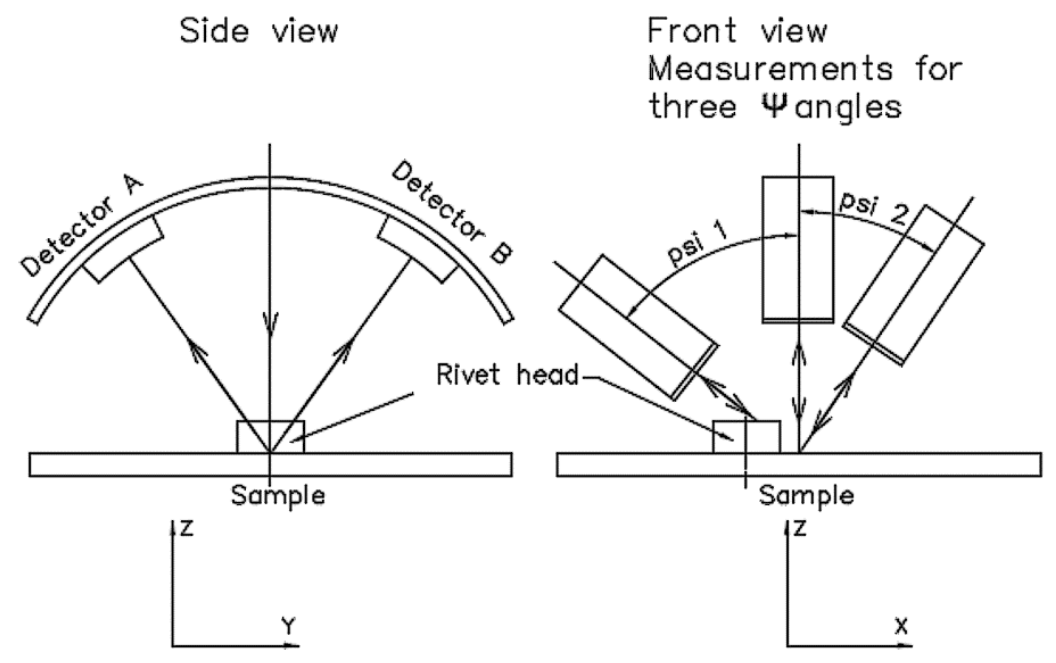

a)

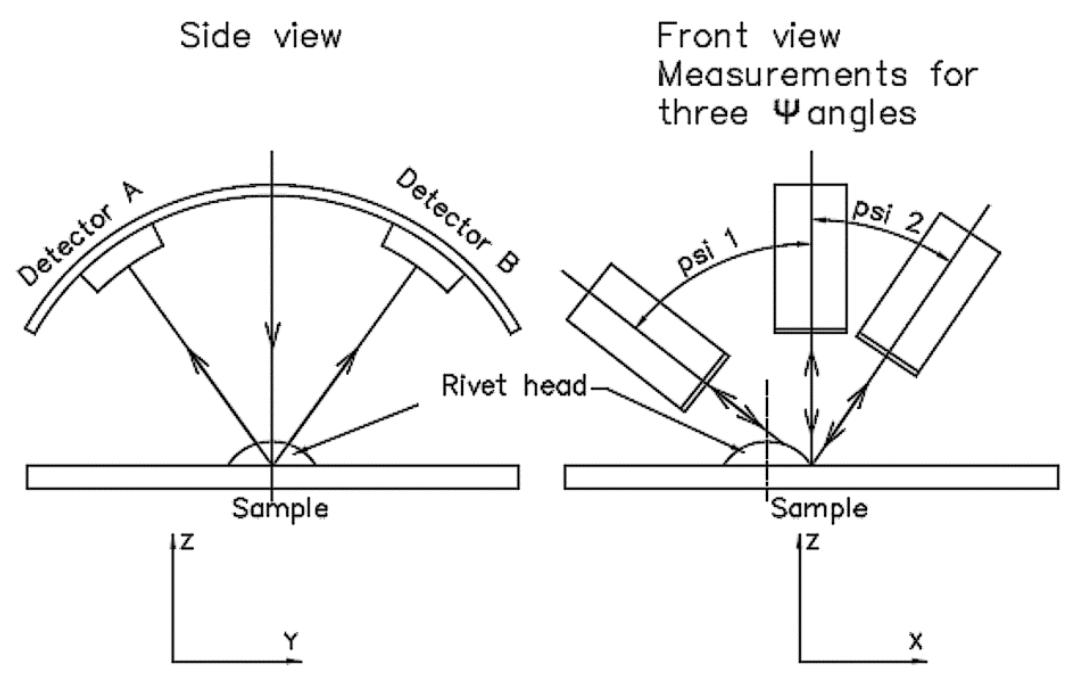

b)

Fig. 4. Analysis of the driven/manufactured head shadow - radial stress measurement, a) by driven head, b) by manufactured protruding head [5]. 
a)

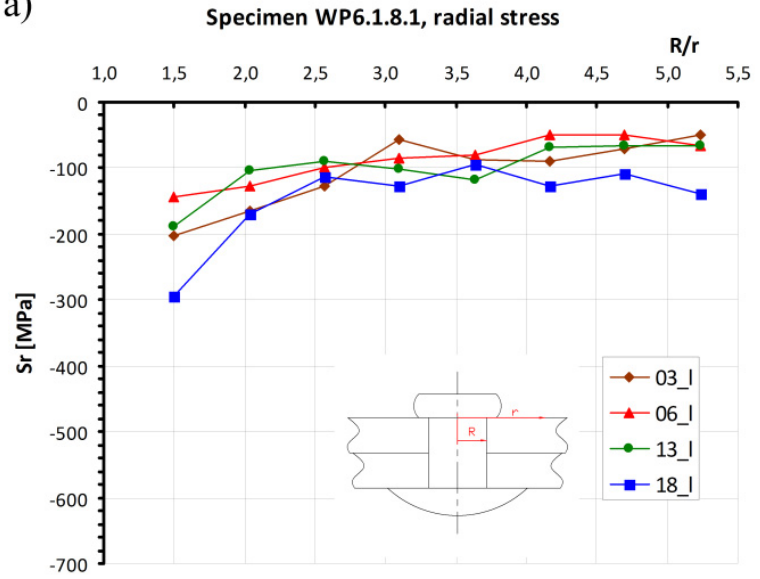

b)

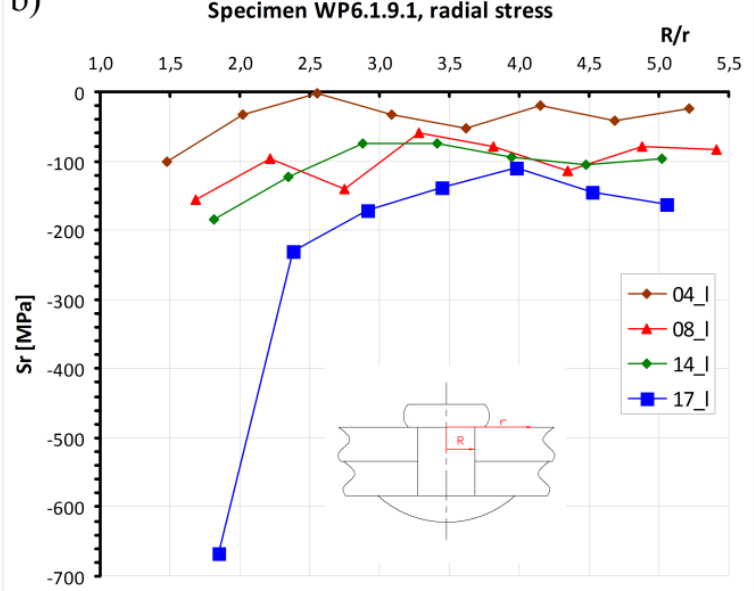

Fig. 5. Results of radial stress XRD measurements for a) brazier rivet BN-70/1121-06, b) rivet with a compensator OST 1 34040-79 [13].

The strain measurements on the sheet surfaces near the driven heads during riveting process were carried out with strain gauges. The riveting processes were performed on the testing machine with the force control. The measurements were made for a $90^{\circ}$ countersunk head rivet and a brazier rivet (standard and with a compensator). S-shaped plots (reversal strain signal) of strain as a function of squeezing force were recorded, Fig. 6 [6]. This phenomenon was the most visible for the countersunk rivets. A similar shape of strain plots was presented by G. Li at all in paper [7], Fig. 7.

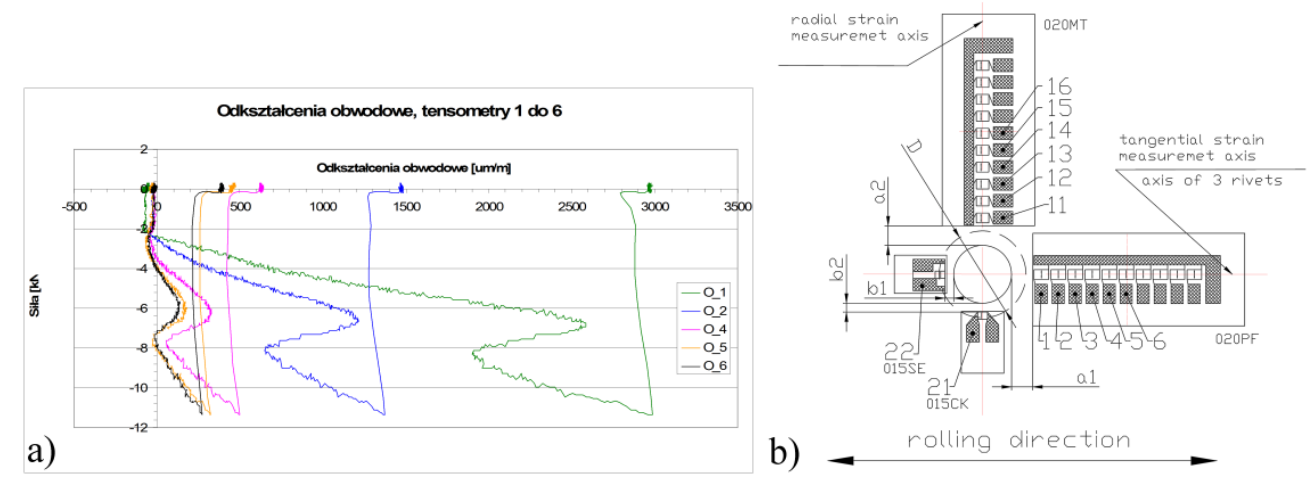

Fig. 6. Tangential strain progress in the sheet at the driven head side for a $90^{\circ}$ countersunk head rivet, recorded by strain gages 1 to 6 (strip gauge) as a function of the squeezing force (a) and the location of strain gauges on the sample (b) [6].

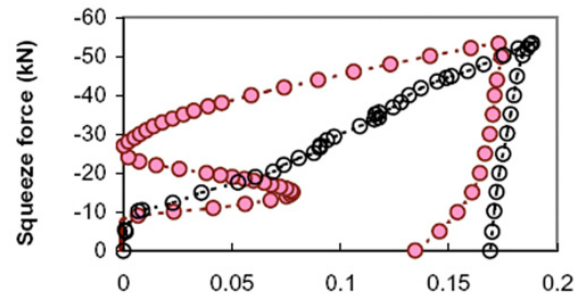

a) Hoop strain (\%) of Gauge 2 during the

O Experimental result

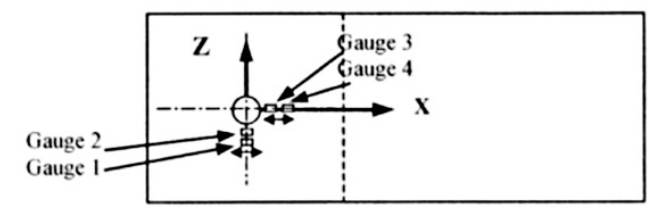

b)

O FEM result

Fig. 7. Strain progress during the riveting process (squeezing force equal to $53,38 \mathrm{kN}$ ), recorded by strain gauge 2 placed on the sheet surfaces near the driven head-comparison of the experimental results with the calculations [7]. 
The analysis of the results obtained by Müller and Hart-Smith [2,3] indicated that when a 1,42time increase in the squeezing force (from 12 to $17 \mathrm{kN}, \mathrm{D} / \mathrm{D}_{0}$ parameter from 1,2 to1,5; where $\mathrm{D}$ is the driven head diameter, $\mathrm{D}_{0}$ - rivet shank diameter) resulted in a twofold increase in the fatigue life, then a three-time increase in the squeezing force (from 12 to $36 \mathrm{kN}, \mathrm{D} / \mathrm{D}_{0}$ parameter from 1,2 to 1,7$)$ resulted in an eleven-time increase, and in the case of riveting with the NACA technology, even an eighty-time increase in the fatigue life. The magnitude of the life increase suggests that a change of the joint formation mechanism took place. The working hypothesis was assumed that, for the significant increase in the squeezing force, the plastic strain level necesssary for adhesive joint formation (called cold welding) was reached. The destruction of an adhesive joint requires a significantly higher force than that needed for the destruction of a mechanical joint. Consequently, the fatigue life of a riveted joint is much higher. The specimens with various types of rivets (countersunk and brazier, standard and with a compensator) and different riveting technologies (normal and NACA) were prepared with a wide range of squeezing forces. The standard anodised layer was removed in some rivets. So far investigations have demonstrated the existence of point and continuous joints on some part of the contact surface between the rivet and the sheet for the countersunk rivet with the anodised layer removed, for $\mathrm{D} / \mathrm{D}_{0}=1,7$. It is not certain, however, whether cold welding occurred in these joints [6]. Results obtained are not unequivocal and do not allow either accepting or rejecting the hypotesis assumed.

\subsection{FEM simulations of the riveting process to determine numerically the residual stress/strain field around the rivet hole}

The extensive FEM analyses of the riveting process were carried out. These covered static (with force control) and dynamic riveting. The axisymmetric and solid models were used. The material and geometrical nonlinearity was taken into account. The Stick-Slip Coulomb friction model (one of five models implemented in the MSC MARC software) was chosen for the calculations, based on the numerical analyses. The materials models were developed based on the monotonic test. The results obtained from the axisymmetric and solid models were very similar, but the calculation time was incomparably shorter for the axisymmetric model $[6,12]$. For frequently repeated analyses (e.g. optimization of the riveting parameters), axisymmetric models are the most convenient. The plots of radial and tangential stresses and strains after riveting are consistent with the results obtained by Müller [8] as well as with the XRD and strain gauge measurements. An acceptable correlation of strain progress during the riveting process in the calculations and the experiment (strain gauge measurements) was not obtained, especially for tangential strains, Fig. 8 $[6,13]$.

b)

tangential strain
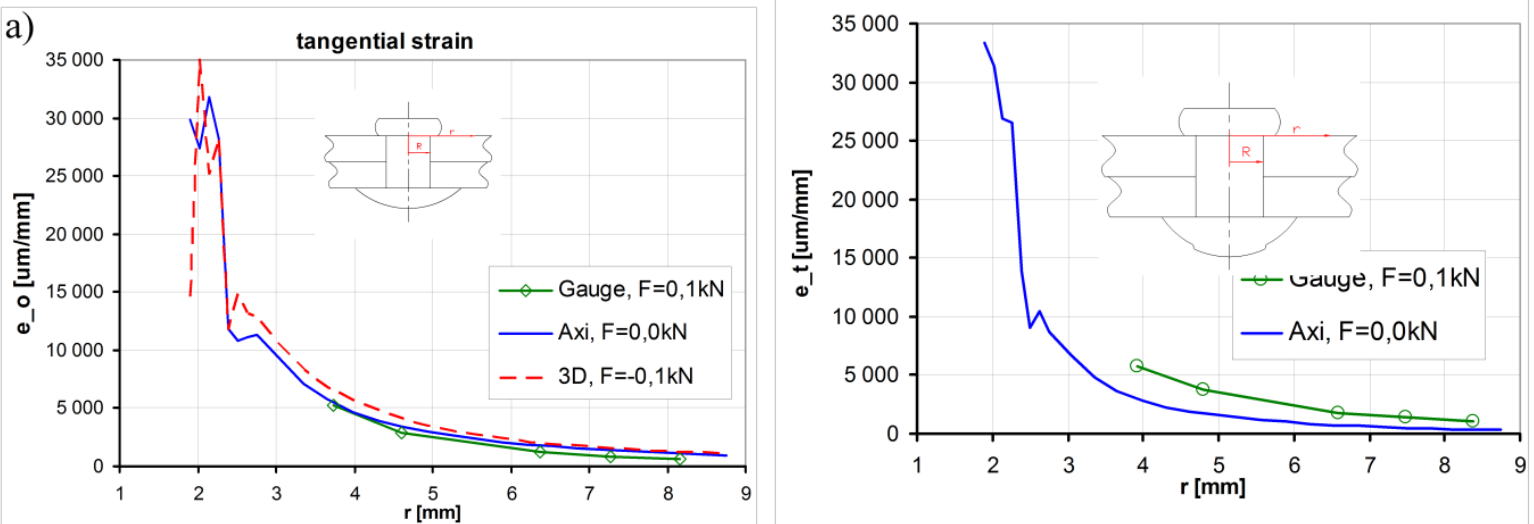

Fig. 8. Experimental and numerical strains as a function of radial position for a) brazier rivet $B N-70 / 1121-06, b)$ rivet with a compensator OST 1 34040-79 [13]. 
Rivets with compensators improve the transfer of the rivet material into the rivet hole and provide better hole filling in the sheet at the manufactured head side (the compensator causes a twofold increase in radial expansion of the rivet hole in this sheet, which means that radial displacements of the hole in both sheets are at the same level), Fig. 9 [12, 13].

Increasing the squeezing force value causes enlarging the plastic zone near the rivet. A considerably bigger effect can be obtained by restricting the driven head diameter (with the riveting set equipped with the ring) without changing its height. This causes a significant stress increase in the sheet, higher squeezing of the rivet shank in the hole and a more uniform stress distribution across the whole thickness of the sheet at the driven head side. Unfortunately, the difference between the radial expansion of the hole in both sheets also increases, while the most desirable effect is when the radial expansion is at the same level in both sheets [14].
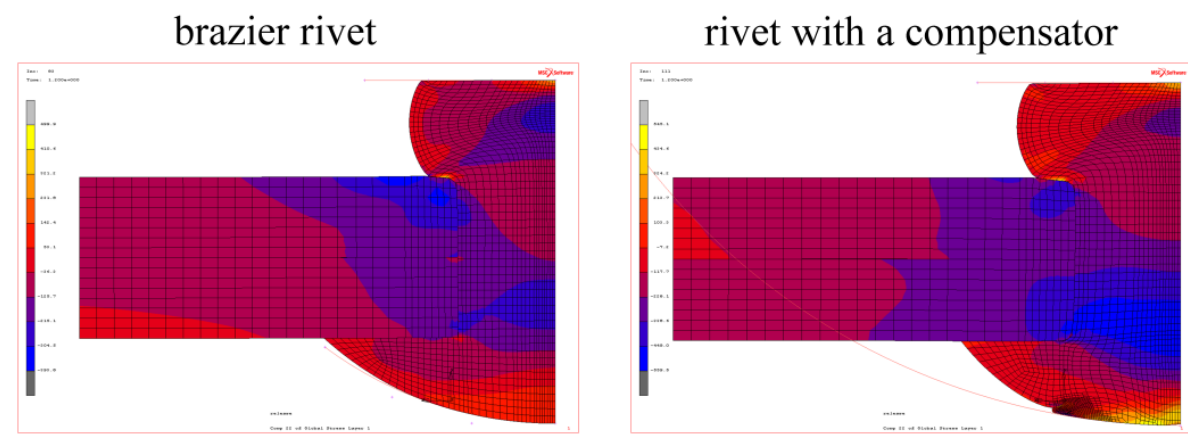

Radial stress
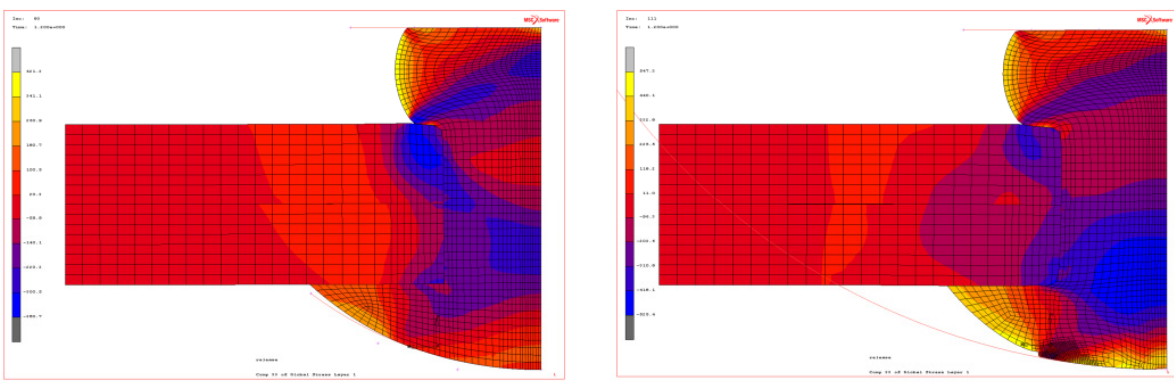

Tangential stress
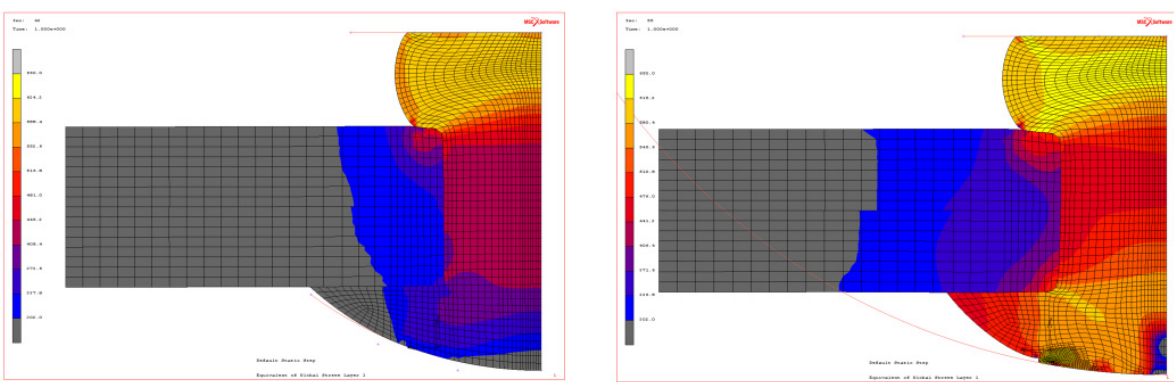

Equivalent stress, gray colour - elastic zone

Fig. 9. Results of axisymmetric FEM simulation of the riveting process. Brazier rivet: standard and with a compensator [12].

The numerical simulation of the riveting process revealed monotonic decrease in average contact stress and equivalent stress caused by an increase of clearance (gap) between the rivet and the hole edge (within the range indicated in the riveting manual). Moreover, in the case of the countersunk rivet, with high clearance, the filling of the countersunk part of the hole is not sufficient, as is indicated by low contact stress values in that area $[14,15]$. 
Standard and reversed (riveting hammer on the side of the manufactured head) dynamic riveting techniques were compared by means of numerical simulations, Fig. 10. Reversed riveting is more appropriate since in the case of standard riveting an undisarable slit between the manufactured head and the sheet appears at the first stage of the process. According to the riveting manual, a special hold-on should be used for the rivet with a compensator. For example, FEM simulations showed that in the case of the $3,55 \mathrm{~mm}$ brazier rivet with a compensator, the most benefitial filling of the rivet hole was obtained for the hold-on radius of $10 \mathrm{~mm}$ (instead of $12 \mathrm{~mm}$, as suggested in the manual) [14].

The FE-analyses of the single rivet were done by the explicit (PAMCRASH) and implicit (MARC) FEA-solvers. It was proved that the implicit solver provided better approximation to reality within the satisfactory calculation time. Although PAMCRASH ran quicker thanks to its higher calculation capacity ( 8 processors compared to 1 used by MARC), further refining of the mesh and time increment would be necessary.

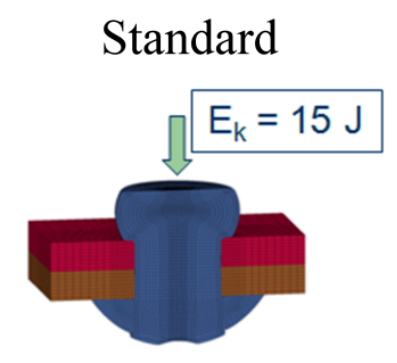

\section{Reversed}
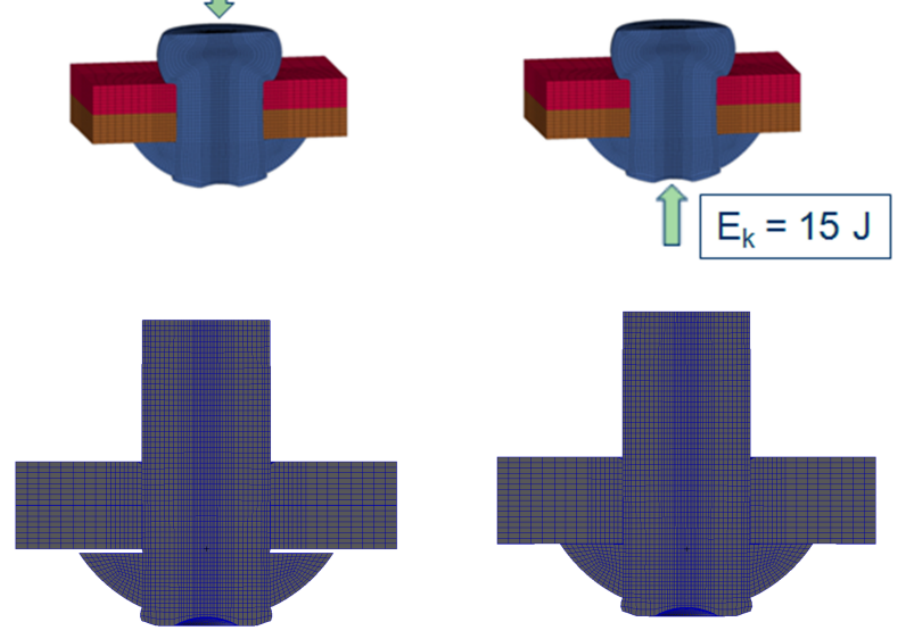

the initial phase of riveting $(\mathrm{t}=0.005 \mathrm{~ms})$
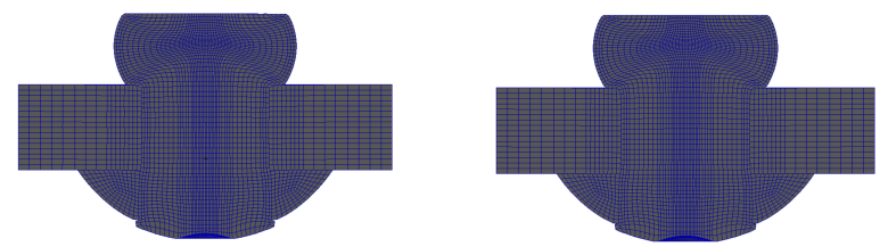

after riveting $(\mathrm{T}=0.08 \mathrm{~ms})$

Fig. 10. Comparison of the normal and reverse riveting.

\subsection{Fatigue tests of specimens with holes and with rivet joints}

The effect of the hole callibration (cold working - the local hardening of the hole and smothing the hole surface) on the fatigue life of the riveted joints was determined, Fig. 11. The research was carried out for five levels of callibration. The fatige life of specimens with callibrated holes as compared to specimens with drilled or drilled and reamed holes was from 1,68 times (for the lowest level of callibration) to 11,4 times higher (for the highest level of callibration), Fig. 12. The 
radial and tangential strain distribiution around the callibrated hole was determined with the Laser Grating Ekstensometry System, Figs. 13 and 14. This technique was used during fatigue tests in order to determine the callibration influence on the local strain amplitude near the hole and near the hole filled with the rivet. For the structural specimens of the commuter aircraft, a fatigue life increase of $65 \%$ for lower load levels and of $112 \%$ for higher load levels was obtained [16].

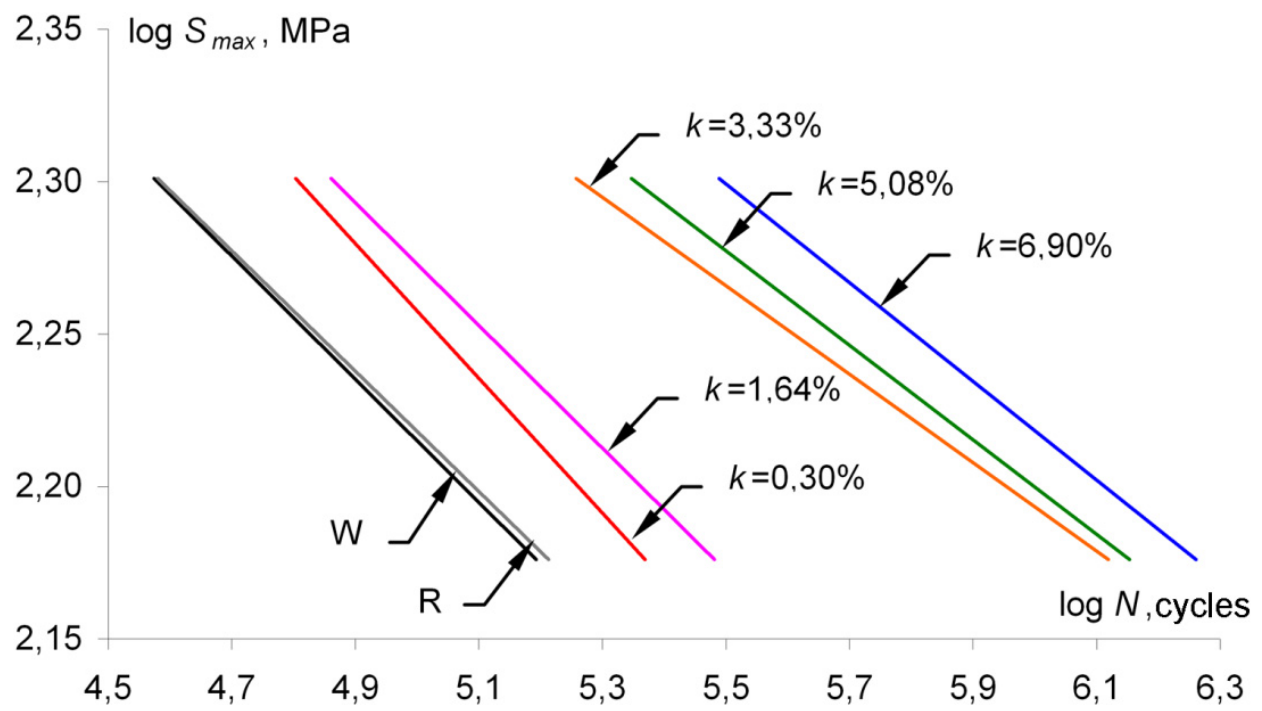

Fig. 11. Fatigue curves obtained for the samples with a hole with various degrees of the calibration $k$ parameter, as well as for the drilled $(W)$ and drilled and milled $(R)$ samples [16].

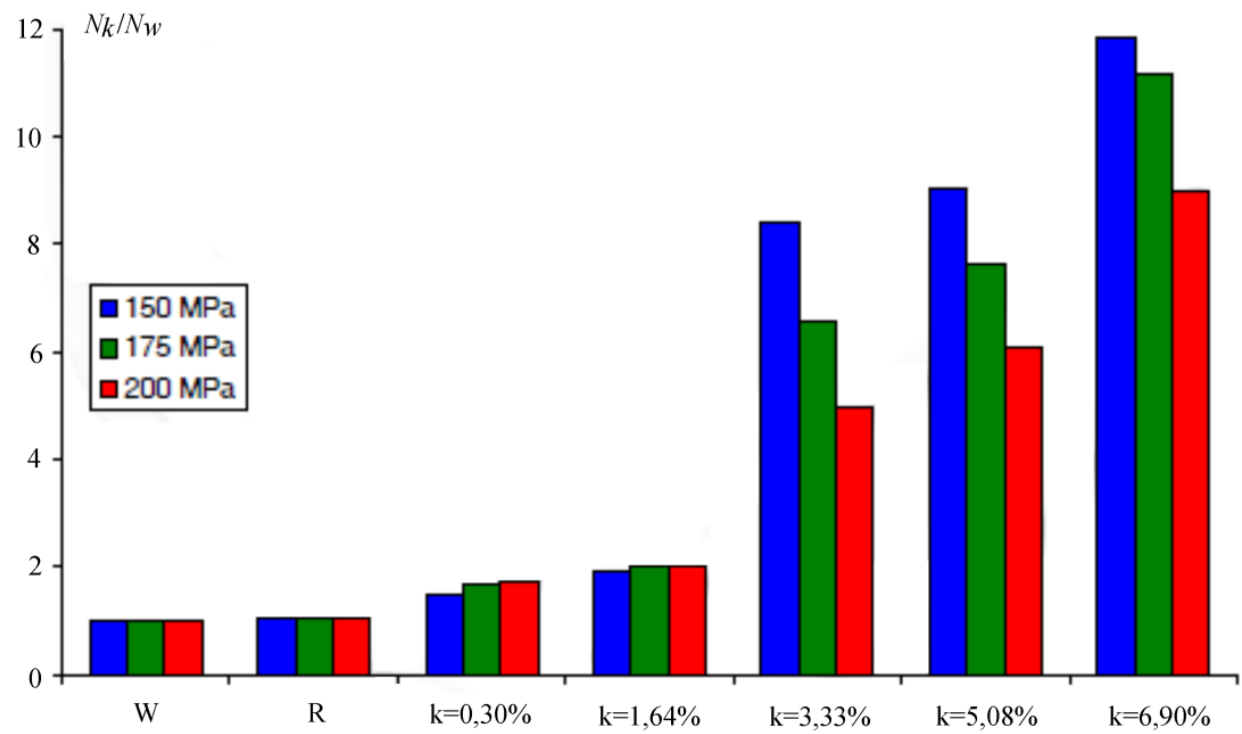

Fig. 12. The ratio of the average fatigue life of calibrated samples $N_{k}$ to the average fatigue life of samples with a hole drilled $N_{w}[16]$. 

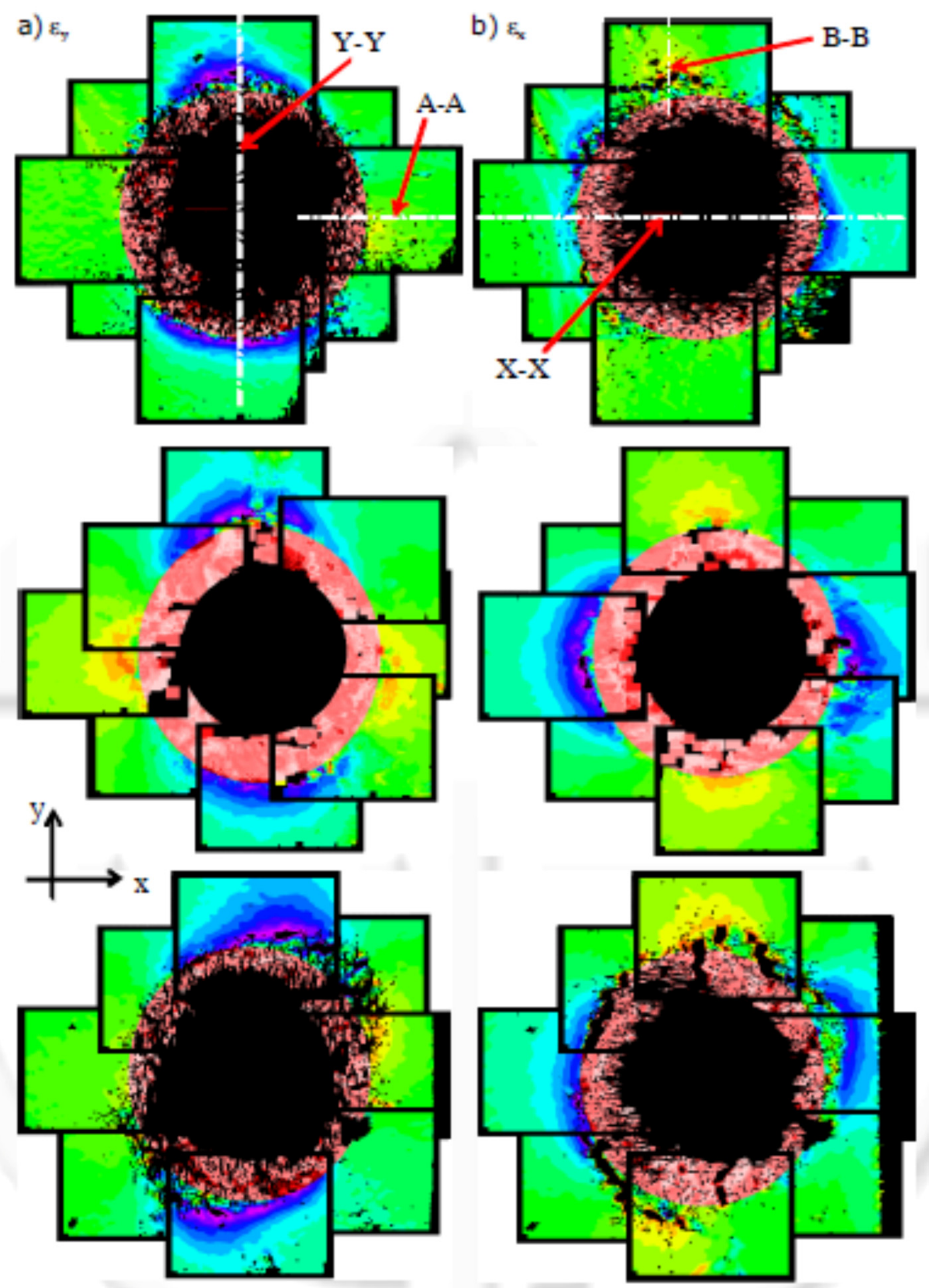

Fig. 13. Strain maps in the $x$ and $y$ directions for the samples with the calibration factor $k$ equal to 6.9, 1.64 and 0.30 [16]. 

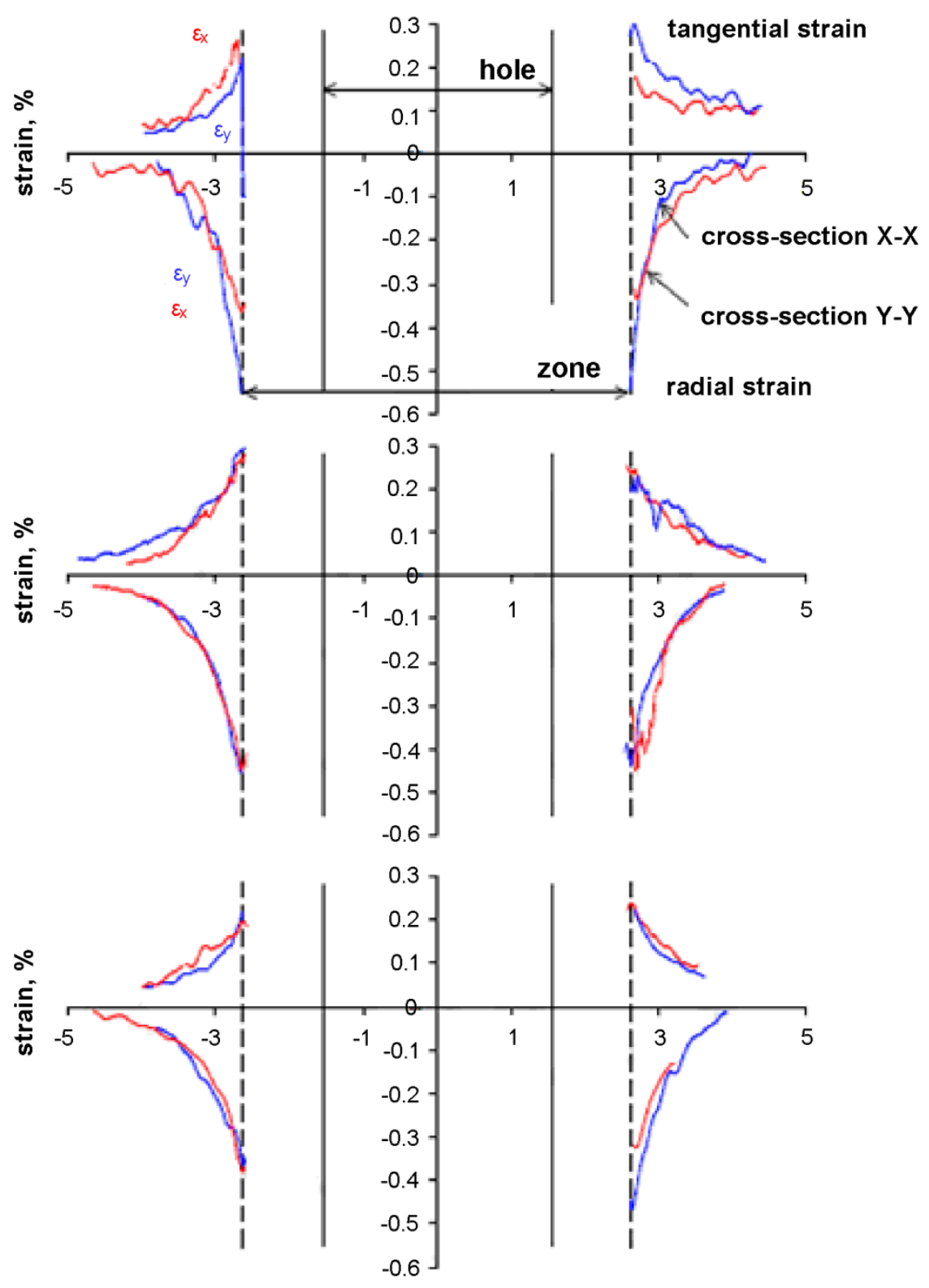

Fig. 14. Courses of radial and circumferential strains in sections XX and YY (marked in Fig. X8), at the hole surroundings for samples with the calibration factor $k$ equal to 6.9, 1.64 and 0.30 [16].

A wide range of fatigue tests were carried out on the riveted lap joint specimens. The specimens represented the longitudinal joints on the aircraft pressurized fuselage. The fatigue properties of riveted joints were compared. The comparison concerned two materials (D16AT and 2024-T3), two types of anti-corrosion layers (alclad and alclad+anodised) and three rivet materials (PA24, PA25 and 2117). Three different rivet types were used to join the sheets i.e. normal brazier rivets (according to the Polish industrial standard BN-70/1120-03), brazier rivets with compensators (according to the Russian standard OST1 34040-79) and universal rivets (according to the US military standard MIL-HDBK-5F). The following design factors were considered in the fatigue tests: rivet pitch and row spacing as well as sheet thickness. The utility of non-standard geometry of the riveted lap joint (staggered thickness joint with stepped thickness) was examined. The effect of various squeezing forces was investigated for a number of configurations. Residual stresses around the rivet are proportional to the squeezing force value. The experimental investigation of the radial expansion of the rivet hole provided further information about the effect of squeezing force, Fig. 15 [17]. 

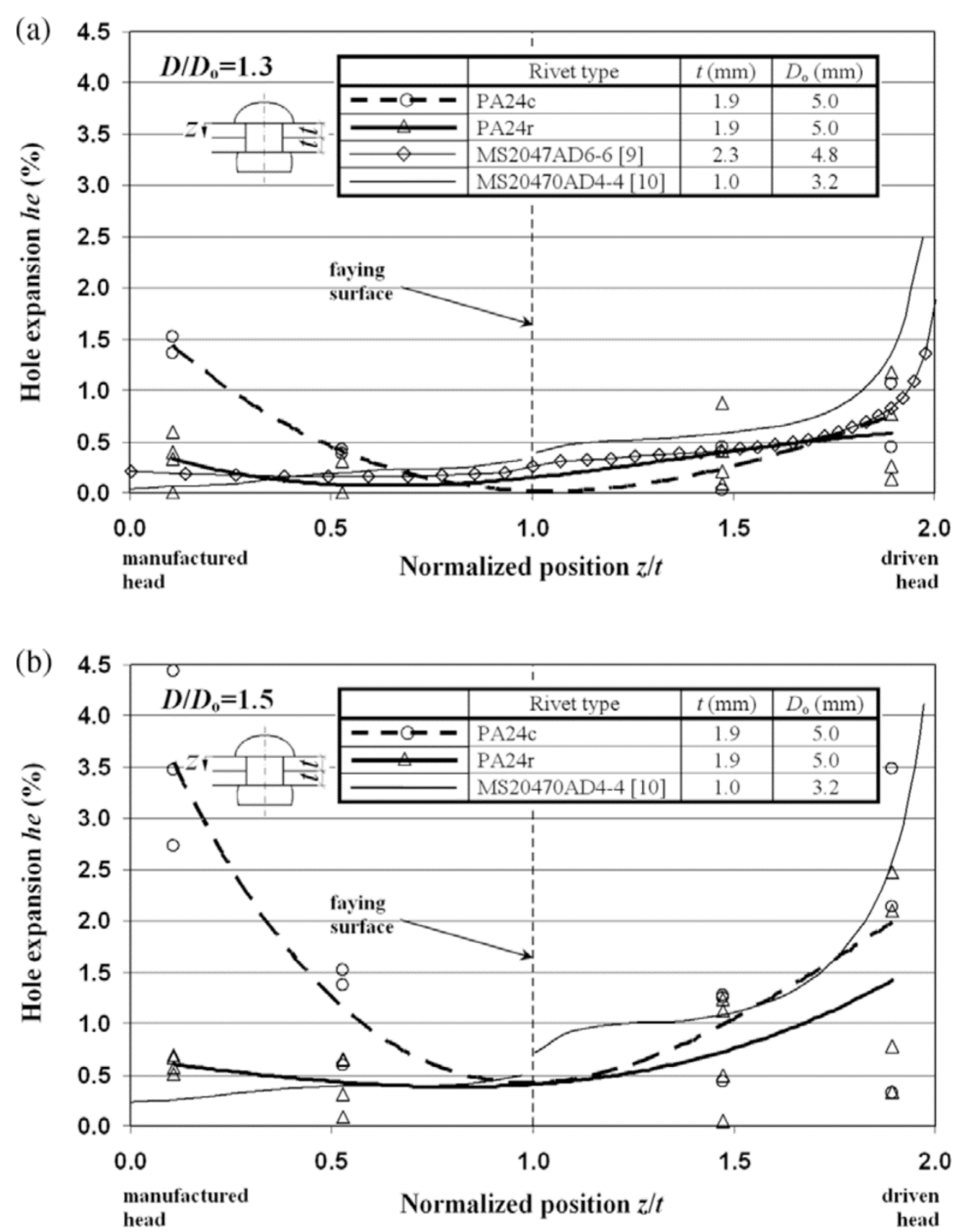

Fig. 15. Comparison between hole expansion for PA24r and PA24c rivets in D16 sheets: (a) $\mathrm{D} / \mathrm{Do}=1.3$; (b) $\mathrm{D} / \mathrm{Do}=1.5[17,18]$.

In Fig. 16 the normalized $\mathrm{D} / \mathrm{D}_{\mathrm{o}}$ and $\mathrm{H} / \mathrm{H}_{\mathrm{o}}$ driven rivet head dimensions are presented against the squeeze stress defined as $\sigma_{\mathrm{sq}}=\mathrm{F}_{\mathrm{sq}} /\left(\pi \mathrm{D}^{2} / 4\right)$. Also plotted in Fig. 16 is the scatter band of data for the 2117-T4 aluminium alloy rivets reported by de Rijck et al. It is seen that the results for the MS and PA24r rivets made of the same material fall within the de Rijck's data scatter band. For the PA24c rivet, the $\mathrm{D} / \mathrm{D}_{\mathrm{o}}$ and $\mathrm{H} / \mathrm{H}_{\mathrm{o}}$ data falling above and below respectively, the scatter band of de Rijck's results confirms higher ductility of this type of the rivet material. The results for the PA25c rivet made of the hardest material are indicative of the opposite trend, as shown in Fig. 16. 


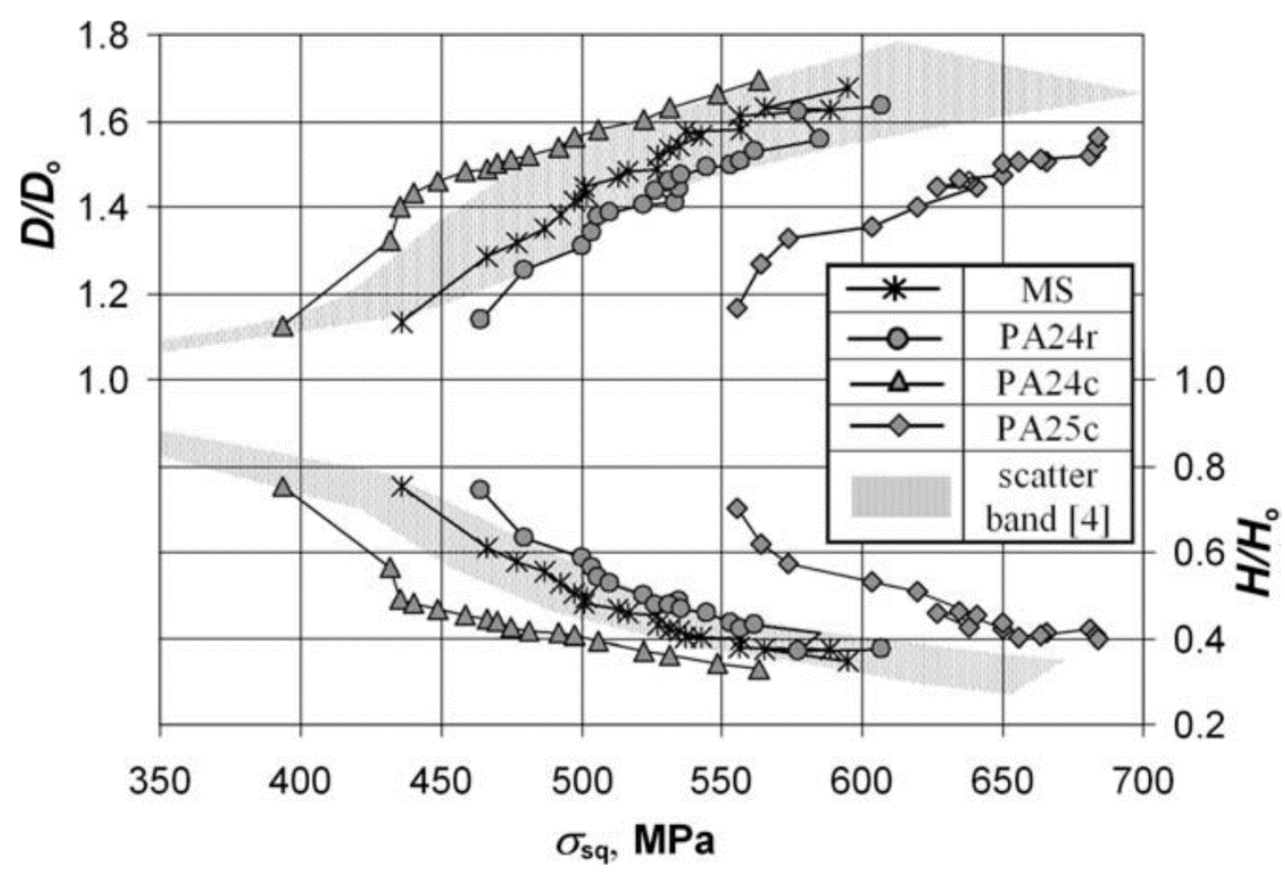

Fig. 16. Normalized driven rivet head dimensions as function of the squeeze stress together with the scatter band by de Rijck et al. [4] for 2117-T4 rivets [17, 18].

Legend:

MS - universal rivet made of the 2117-T4 alloy according to the American standards MS20470

PA24r - round rivet made of the PA24 alloy according to the Polish industry standard BN-70/1121-03

PA24c - brazier rivet with compensator made of the polish PA24 alloy (rivet geometry according to the

Russian standard OST 1 34040-79)

PA25c - brazier rivet with compensator made of the polish PA25 alloy according to the Russian standards OST $134040-79)$

[4] de Rijck JMM, Homan JJ, Schijve J, Benedictus R. The driven rivet head dimensions as an indication of the fatigue performance of aircraft lap joints. Int. J Fatigue 2007;29, pp. 2208-18.

a)
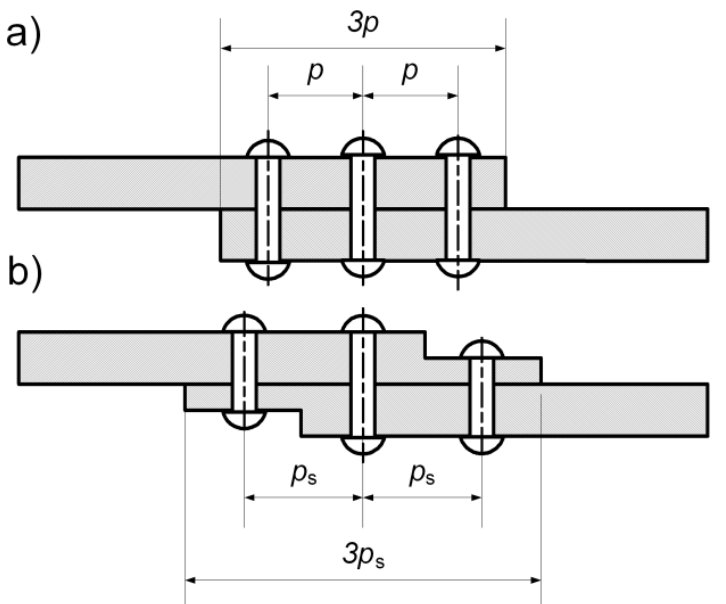

c)

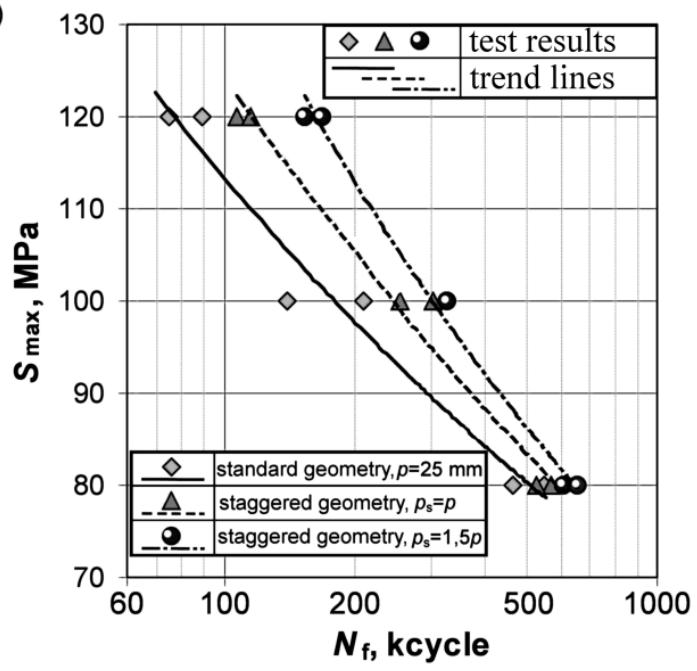

Fig. 17. Effect of sheet thickness staggering in the overlap region on the joint fatigue life: a) standard joint geometry, b) staggered thickness geometry, c) fatigue tests results [3].

The fatigue tests have proved that the staggered thickness lap joints have better fatigue properties than standard joints, Fig 17. [17]. It should be emphasized that this is the first experimental confirmation of this interesting concept, which allows improving fatigue life without 
a weight penalty. The analyses with the Schijve model have proved that the main reason for this improvement is the reduction of the secondary bending in the outer rivet row, caused by the appropriate reduction of the sheet thickness. An increase in fatigue life should be explained also by a reduction of the secondary bending connected with an increase of the rivet rows spacing and a reduction of sheets thickness. The usage of joints with more than two rivet rows is wellgrounded from the fatigue point of view. Three-row joints have higher fatigue life than two-row joint, even in the case of the same length of overlap.

It has been confirmed that fatigue crack growth in riveted joint usually takes the form of multisite damage. Cracks always nucleate on the faying surface of sheets, Fig. 18. This indicates that crack initiation is connected with fretting between sheets. Cracks were visible in the outer surface at the last part of the joint's fatigue life, especially in the case of specimens with thick sheets. This confirms the need to use an appropriate non-destructive technique during periodic inspection in order to detect cracks before they are visible on the outer surface of the skin.
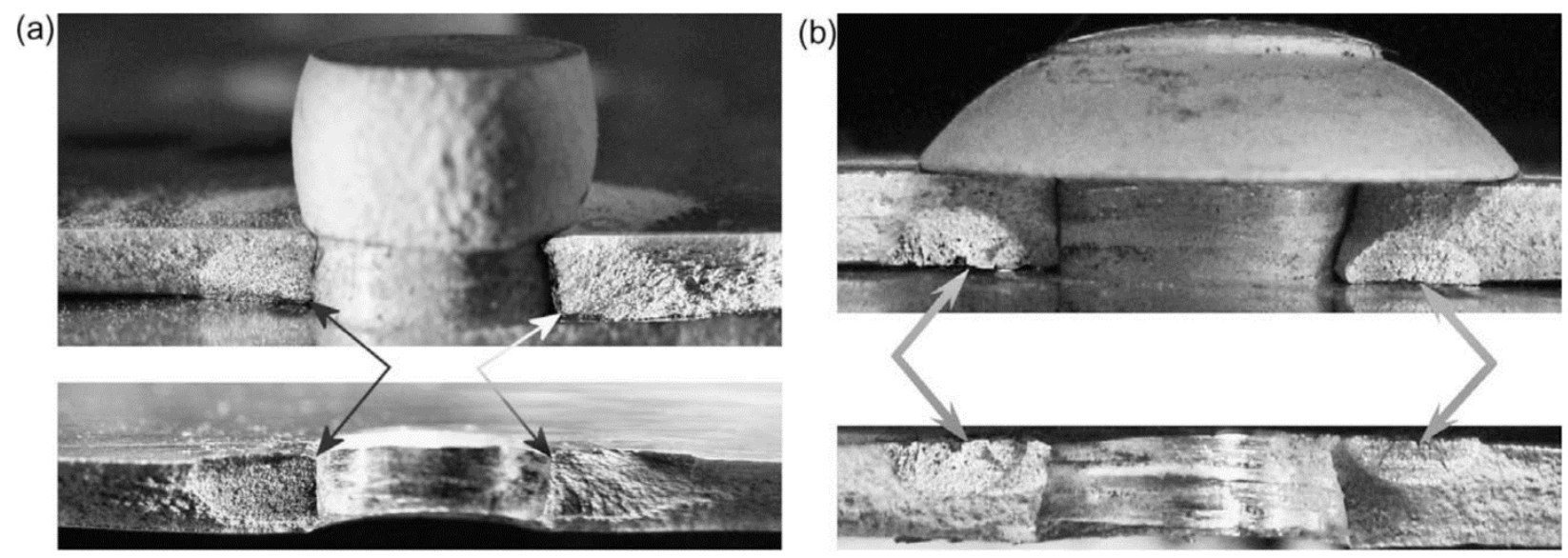

Fig. 18. Effect of squeeze force on the crack initiation site: (a) corner crack at rivet hole edge $(\mathrm{D} / \mathrm{DO}=1.3)$; (b) semi-elliptical crack slightly away from hole $(\mathrm{D} / \mathrm{D} 0=1.5)$ [17, 18].

The anodized layer on the sheets used as an anticorrosion protection decreases the fatigue life of a joint. This confirms the observations presented in the literature.

In the case of joints with thick sheets (e.g. $\mathrm{t}=2 \mathrm{~mm}$ ) assembled with the rivets with a compensator made of PA24 alloy, the fatigue life was substantially higher than that of joints with universal or brazier rivets, made of the same alloy. When compensators were removed from the rivets (before riveting), the fatigue life of joints was the same as in the case of universal and brazier rivets. Based on the performed measurements of hole expansion it was found that the fundamental reason for higher fatigue life of the specimens with rivets with compensators was better hole filling caused by compensators. Joints of thin sheets (e.g. $\mathrm{t}=0.8 \mathrm{~mm}$ ) demonstrate lower fatigue life when using rivets with compensators then in the case of other rivet types mentioned above.

Joints of thin and thick sheets demonstrate definitely higher fatigue life than joints of two thin sheets, especially when the driven head is on the thick sheet side. This should be connected with the fact that such a configuration prevents the development of thin sheet damage. Joints of thin sheets are susceptible to such damage (sheet deformation, damage of the sheet surface under the driven head).

An extensive programme of measurements and analyses of load transfer in the lap joint was carried out in view of the prospective fatigue life estimation. The programme covered measurements of the axial rivet forces in the overlap area and measurements of the rivet flexibility in relation to various squeezing forces. The results obtained enabled positive verification of the currently used analytical solution of load transfer $[18,19]$. 
The fractographic analyses of the riveted lap joint have proved that the squeezing force affects the joint damage mechanism (due to the stress concentration at the hole or the fretting phenomenon). The squeezing force influence should be thus taken into account in the fatigue life predictions. At the same time, the squeezing force influence on the load distribution in the joint has been proved. Therefore, the currently used analytical procedure of calculating the lateral forces in the overlap area could give incorrect results [17].

The theoretical analyses confirmed with the strain gauge measurements have indicated the presence of high secondary bending. Simple analytical methods based on the beam theory and described in the literature as a tool for estimating secondary bending in the riveting joints with the force eccentricity, the Schijve model in particular, have proved to be a convenient instrument for the evaluation of the bending parameter, (defined as nominal bending stress in the critical rivet row divided by applied load). The validation of the Schijve model was carried out with the strain gauge measurements of bending stresses in the lap joint. The beam models' ability to adequately estimate the influence of the geometrical configuration and the load level on the secondary bending in the joints with the eccentricity was confirmed [19].

The new optical methods of the rivet deformations measurements were developed. They could be very useful for verification of the numerical calculations.

\subsection{D and 3D FEM stress-strain modelling of rivet joints}

The FEM calculations of the lap joint and the single strap butt joint were performed. In the case of the simple joint models, the sheets were modeled with shell elements in the sheet middle layer (secondary bending, which is an inherent feauture of such joints, was taken into account). Several rivet models were tested. For the analysis of the joint with many rivets, the model consisting of shell elements as well as the GAP contact elements and rigid MPC elements was developed [19]. This model allows taking into account secondary bending as well as contact interactions between the sheets and the rivet shank with a relatively small number of nodes and contact elements. At the first stage of the analysis, temperature was defined for rivet elements in order to introduce residual stresses. At the second stage of the analysis, the joint was tensioned by applied force or displacements.

The lap joint with two rivets (two rows) was analysed with the solid model. Geometrical and material nonlinearity was taken into account. At the first two stages, the sequential riveting process of two rivets was simulated. At the third stage, the joint was tensioned. Important strain changes on the sheet surface near the rivet were observed during tension. This phenomenon was recorded during the fatigue tests by the micro strain gauges placed in the specimen axis near the rivet manufactured head [6]. Due to the problems with the calculation convergence, the results for the high load level were not obtained.

The analysis of voids nucluated in the alluminium alloy during tension was carried out based on the SEM fractographic observations. The change in the material structure in the area of high tension was recorded. Cracks occur close to the inclusions during tension of the sheet. Cracks appear at the boundary of the inclusions. In numerical simulations of structural elements, the materials are described in macroscopic terms e.g. the elasto-plastic material model which takes into account damage of the material as a result of void growth, proposed by Gurson. This model enables a more realistic simulation of the sheet necking and observation of the slit growth during tension as well as exact determination of the sheet breaking moment based on the reaction value [14]. 


\subsection{Applying FEM to develop a stress intensity factor solution for cracks emanating from a rivet hole}

Comparative calculations of the stress intensity factor (SIF) for the corner crack growing from the hole - cylindrical and with the countersunk - in rectangle plates were performed using different methods. The Newman and Raju equations and FRANC3D (the boundary element method) software as well as the MSC MARC (the finite element method) software with the Virtual Crack Closure Technique (VCCT) were employed. Afterwards, the SIF calculation for a crack growing from one of the holes in the lap-joint specimen made of D16 alloy was performed. The fatigue tests of this specimen with crack growth measurement were carried out at the Krakow University of Science and Technology (AGH), a member of the IMPERJA consortium. SIF Calculations for a few crack sizes were performed with the FEM and VCCT methods. The SIF for the complex load was determined as the superposition of the individual SIFs for each load component i.e. tension, bending and pin loading calculated in separate calculations. Moreover, crack growth predictions with the NASGRO equation implemented in the AFGROW software were carried out [6].

\section{APPLICATION RESEARCH}

\subsection{Fatigue testing and FEM analysis of specimens representing selected structural details of an airframe and FEM stress-strain analyses}

The constant (CA) and variable amplitude (VA) fatigue tests were carried out for four types of specimens of the riveted joints in the wings and fuselage of a commuter class aircraft, manufactured by the Polish and Czech aerospace industry.

In a sample of a strap joint with an additional ribs shelf added in the process of riveting, additional procedure - calibrating holes for rivets - causes an increase in fatigue life and transfer of crack initiation from the strap (in the inner row of rivets - difficult to detect) to the sheet (in the outer row of rivets - easy to detect), Fig. 19 and 20.

a)

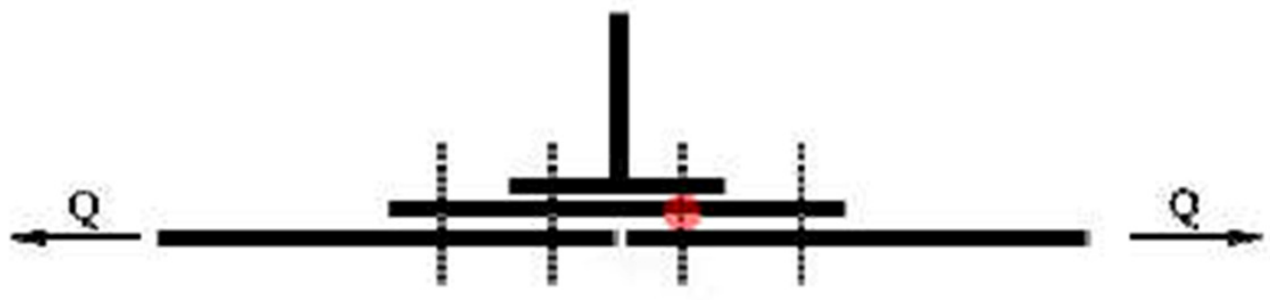

b)

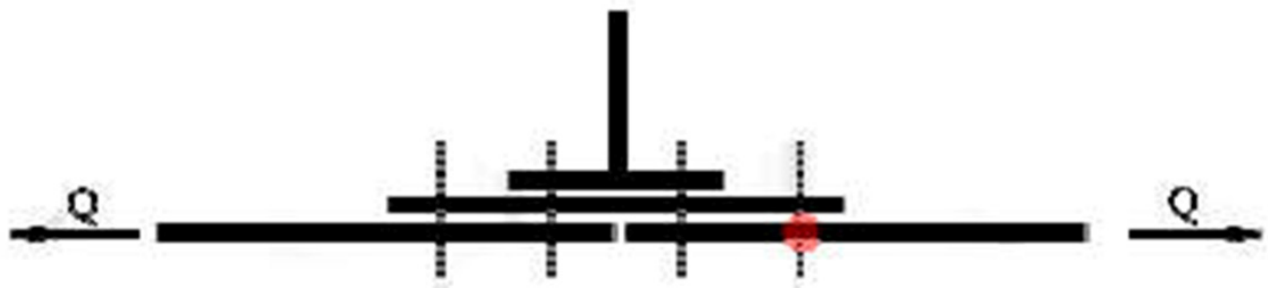

Fig. 19. Fatigue crack initiation places typical for a strap joint with an additional ribs shelf in the initial state (a) and after calibrating holes for the rivets (b) [16]. 


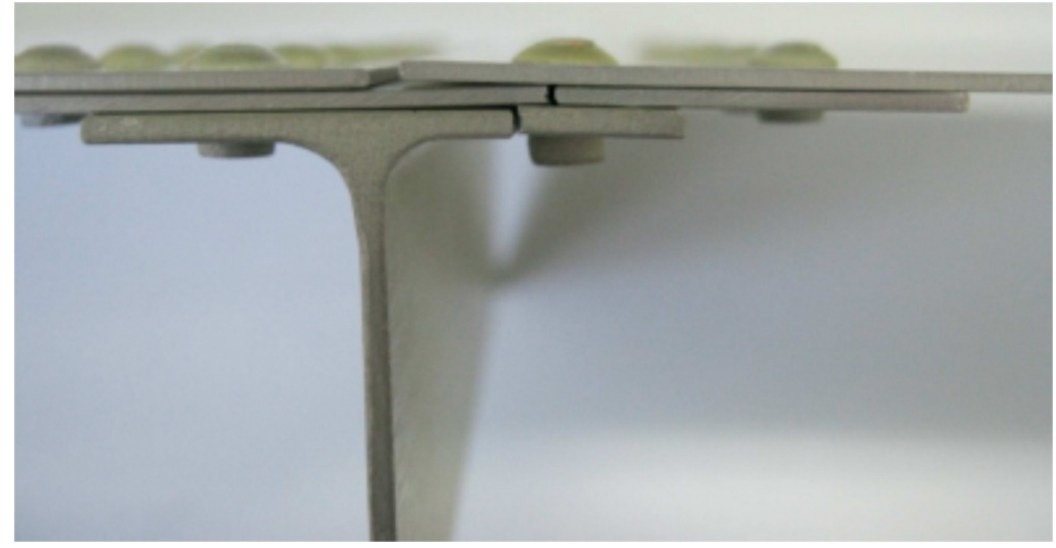

a)

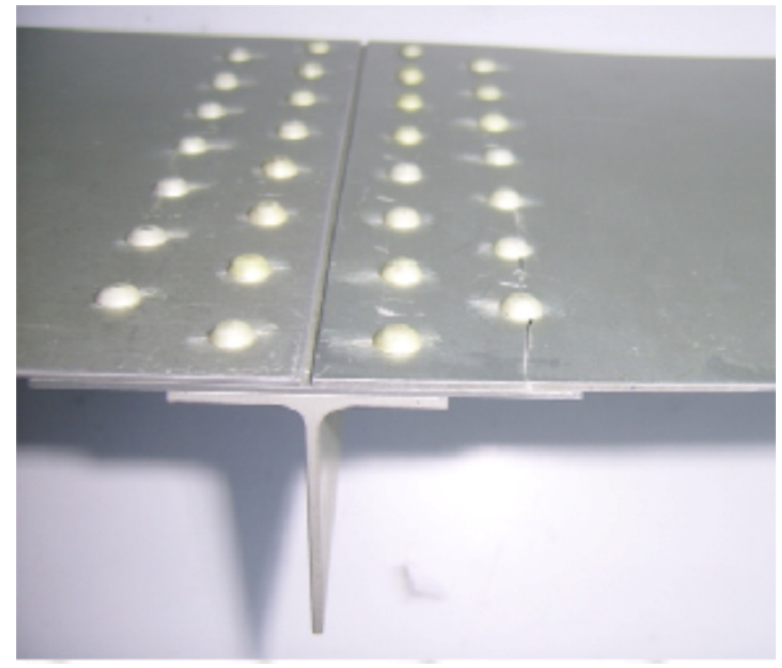

b)

Fig. 20. Fatigue crack initiation sites in the sample in the initial state (a) and after calibrating holes for the rivets (b) [16].

The FEM analysis of the joint in the wing was performed at three different complexity levels, namely considering the part of the wing (three bulkheads at each side of the rib at the investigated joint), I level local model - the shell model of the joint corresponding to the specimen subjected to the fatigue tests, and II level local model - the solid models of the single rivet.

It is practically impossible to model rivets in the analysis of a big part of the structure because it contains several hundred rivets. A submodelling technique might be quite useful in such cases, which involves building a more precise (local) model covering a smaller area and setting boundary conditions based on the analysis of a big (global) model. The results, presented in Fig. 21, indicate that if the models (global and local) differ considerably in flexibility, it is better to use stresses instead of displacements as boundary conditions [20 19].

Four versions of the model were analyzed:

1. merging nodes in rivet axes - no secondary bending

2. rivet as a single rigid $\mathrm{MPC}$ - secondary bending included

3. rivet with contact elements (GAP) - no secondary bending

4. rivets ignored - no secondary bending 

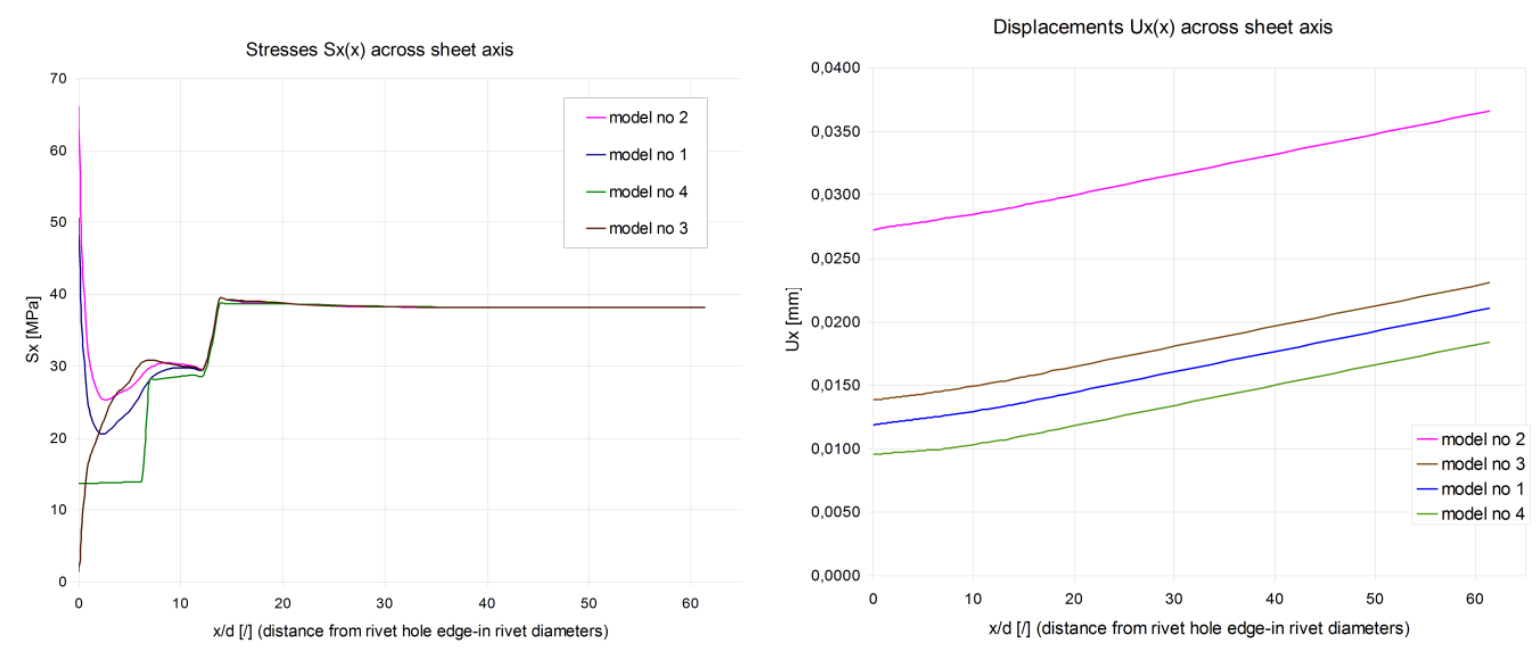

Fig. 21. Stresses and displacements in tension direction across the sheet axis [6].

Two FEM models of complex joints with 7 rivets (3.5 rivets in the FEM model thanks to the symmetry) were analyzed. The demand of the MARC solver was anyhow too great and the FEmodels had to be built in a coarser manner than for the single-rivet analyses, or the convergence criterion would not have been fulfilled.

The applicability of the BUSH (springs) elements for the shell modeling of the riveted joints was confirmed by comparison of the complex solid and simplified shell FE-models. These elements are used instead of the rivets and enable defining more complex stiffness characteristics. Based on the previous lengthy analyses with solid models, the quick response time of this new solution is promising and worthy of further investigation.

\subsection{Estimation of Fatigue Life of the Riveted Joints}

The cumulative fatigue damage calculations of the structural specimens were performed according to the method recommended by the USA Federal Aviation Administration in AC2313A. The fatigue curves of riveted joints were derived from the literature and developed based on the fatigue tests performed as part of the IMPERJA project. The results of the FEM analyses of these specimens were used for the fatigue calculations with the MSC FATIGUE software. The high scatter and poor correlation with the experimental results were observed. In the calculations, the presence of the residual stresses after the riveting process was neglected. The residual stresses were taken into account in the fatigue calculations with the PragTic software (developed by J. Papuga, Evector company). The calculations were performed with the uniaxial (Smith-WatsonTopper, Landgraf) and multiaxial (Socie) methods. The obtained results were very conservative, especially for uniaxial methods (higher for the SWT than for the Landgraf methods; the methods differ in the way of the mean stress correction). The assumed material properties heavily influence the calculation results. The nodes of the numerical model with the lowest fatigue life were not always coincident with the points where the cracks nucleated in the experimental test [6].

The possibility of fatigue life predictions with the estimated fatigue curves (in terms of strain determined based on tensile tests) was investigated. This method was found unsuitable for 2024-T3 and D16CzATW aluminum alloys. Based on the selected loading sequence compiled with the FALSTAFF, seven methods of fatigue life estimation were verified. For the stress approach using the Wöhler diagram, the satisfactory correlation with the experiment results was obtained for the Kwofie's model. For the strain approach using the Morrow plot, the best results were obtained for the SWT parameter modified by Bergmann [16]. 


\section{CONCLUSIONS}

Many practical results possibly useful for the aerospace industry were obtained. These concern appropriate selection of the rivet geometry, size and material as well as the riveting process parameters.

Of special value is demonstrating the dependency between squeezing force and the fatigue life of the joints. Higher squeezing force is connected with higher radial expansion of the rivet hole generating residual compressive stresses around the rivet - which is benefital from the fatigue point of view.

Riveted staggered lap joints have better fatigue properties than standard joints.

Of particular importance is the observation that the fatigue performance of the joint is determined by the squeezing stress rather than the relative size of the driven head, as it is commonly accepted in the industry. The squeezing force effect should be taken into account in the fatigue life predictions since it influences the joint damage mechanism (due to the stress concentration at the hole or fretting).

The fatigue tests have proved that fatigue life of riveted joints is somewhat lower for alclad and anodised sheets than for alclad sheets. This observation agrees with the literature.

Based on the database generated under the project it has been demonstrated that for the lap joints of various geometrical configurations but the same sheet material, rivet type and squeezing stress, a good consolidation of the fatigue test results in the common scatter band is obtained when fatigue lives are presented in terms of the combined tensile and bending stress amplitudes.

The results of the research carried out under the project were published in one $\mathrm{PhD}$ thesis, six monographs (two in English) and two monograph chapters, forty-five articles (twenty-two in English), forty-one conference papers (fourteen in English, presented at international conferences) and nineteen internal reports (four in English).

\section{REFERENCES}

[1] Gnarowski W.: Analiza Kosztów Operacyjnych Bezpośrednich (DOC)w zależności od resursu godzinowego dla samolotu ,Skytruck". Unpublished report by the Institute of Aviation no. BPP1/15A/07, 2007.

[2] Skorupa A., Skorupa M.: Effect of Production and Design Related Factors on the Fatigue Behavior of Riveted Joint in Aircraft Fuselage. Fatigue of Aircraft Structures. Monographic Series. Institute of Aviation Scientific Publication, Warsaw, Poland 2010.

[3] Skorupa A., Skorupa M.: Effect of Production and Design Related Factors on the Fatigue Behavior of Riveted Joint in Aircraft Fuselage. Fatigue of Aircraft Structures. Monographic Series. Institute of Aviation Scientific Publication, Warsaw, Poland 2010.

[4] Boroński D., Mroziński S., Lipski A., Szala J.: Metody doświadczalne $w$ badaniach materiałów stosowanych na poszycia samolotów i połaczeń nitowych. Wybrane zagadnienia, ed. by J. Szali, Wydawnictwa Naukowe Instytutu Technologii i Eksploatacji - PIB w Radomiu, Radom, 2010.

[5] Kaniowski J., Korzeniewski B., Merja Hakanen (2011). Methodology of Residual Stress Measurements for Rivet Joints. Fatigue of Aircraft Structures, ISSUE 2011. Institute of Aviation Scientific Publication. 
[6] Kaniowski J. i in.: Raport końcowy z realizacji projektu badawczego specjalnego nr EUREKA/59/2006, MNiSzW, Warszawa 2011. Poprawa Trwałości Zmęczeniowej Połączeń Nitowych Stosowanych w Konstrukcjach Lotniczych (Improving the Fatigue Performance of Riveted Joints in Airframes).

[7] Li, G., Shi, G., Bellinger N.C. (2006). Studies of Residual Stress in Single-Row Countersunk Riveted Lap Joints. Journal of Aircraft, Vol. 43(3).

[8] Müller R.P.G. (1995). An experimental and numerical investigation on the fatigue behaviour of fuselage riveted lap joints. $\mathrm{PhD}$ thesis, Delft University of Technology.

[9] Müller R.P.G., Hart-Smith L.J. (1997). Making fuselage riveting lap splices with 200-year crack-free fatigue life. ICAF 1997 Fatigue in new and ageing aircraft. Proceedings of the $19^{\text {th }}$ Symposium of the International Committee of Aeronautical Fatigue, Edinburgh, EMAS Publishing, pp. 499-522.

[10] Skorupa M., Skorupa A., Machniewicz T., Korbel A. An experimental investigation on the fatigue performance of riveted lap joints. In ICAF 2009 Bridging the Gap between Theory and Operational Practice, 27-29 May 2009, pp. 449-473.

[11] Kaniowski J., Korzeniewski B,: Tensometryczne badania wplywu czynników technologicznych $w$ procesie nitowania na pole naprężeń własnych $w$ blasze wokót połaczenia nitowego. Unpublished report by the Institute of Aviation no GR/0031/BP4/2010, 2010.

[12] Wronicz W., Kaniowski J., Korzeniewski B., Gadalinska E. (2011). Experimental and Numerical Study of Stress and Strain Field Around the Rivet. ICAF2011. Proceedings of the $26^{\text {th }}$ Symposium of the Int. Committee on Aeronautical Fatigue, Canada, 29-31 May 2011. Springer, 2011.

[13] Wronicz W., Kaniowski J. (2011). Experimental and Numerical Study of Strain Progress During and After Riveting Process for Brazier Rivet and Rivet with Compensator squeezing force and rivet type effect. Fatigue of Aircraft Structures, ISSUE 2011. Institute of Aviation Scientific Publication.

[14] Szymczyk E. i in. (2011). Poprawa Trwałości Zmęczeniowej Połaczeń Nitowych Stosowanych $w$ Konstrukcjach Lotniczych (Improving the Fatigue Performance of Riveted Joints in Airframes). Raport końcowy $\mathrm{z}$ realizacji projektu badawczego specjalnego $\mathrm{nr}$ EUREKA/62/2006. Warszawa: MNiSzW.

[15] Sławiński G., Niezgoda T., Szymczyk E., Jachimowicz J. (2010). Numerical study of the influence of shape imperfections on residual stress fields in a rivet hole. Journal of KONES, vol. 17(2), pp. 427-434. Warszawa: European Science Society of Powertrain and Transport Publication.

[16] Lipski A. i in. (2011). Poprawa Trwałości Zmęczeniowej Połaczeń Nitowych Stosowanych w Konstrukcjach Lotniczych (Improving the Fatigue Performance of Riveted Joints in Airframes). Raport końcowy $\mathrm{z}$ realizacji projektu badawczego specjalnego $\mathrm{nr}$ EUREKA/61/2006. Warszawa: MNiSzW.

[17] Skorupa M. i in. (2011). Poprawa Trwałości Zmęczeniowej Połaczeń Nitowych Stosowanych $w$ Konstrukcjach Lotniczych (Improving the Fatigue Performance of Riveted Joints in Airframes). Raport końcowy $\mathrm{z}$ realizacji projektu badawczego specjalnego $\mathrm{nr}$ EUREKA/60/2006. Warszawa: MNiSzW.

[18] Skorupa M., Skorupa A., Machniewicz T., Korbel A. (2010). Effect of production variables on the fatigue behaviour of riveted lap joints. International Journal of Fatigue, 32(2010) pp. 996-1003.

[19] Skorupa M., Korbel A. (2008). Modelling the Secondary Bending in Riveted Joints with Eccentricities. The Archive of Mechanical Engineering, Vol. 55(4), pp. 369-387.

[20] Wronicz W., Jachimowicz J., Kaniowski J. (2009). Methods for global and local FEM analysis of riveted joint on the example of the PZL M28 Skytruck aircraft. Fatigue of Aircraft Structures, ISSUE 2009. 